Bangladesh J. Bot. 48(3): 507-511, 2019 (September)

\title{
EVALUATION OF ANTIOXIDANT AND ANTIMICROBIAL ACTIVITIES OF OLIGOMERIS LINIFOLIA (VAHL) J.F. MACBR.
}

\author{
Muhammad Nadeem Khan*, Muhammad Wasim Khan ${ }^{1}$ \\ and Rahmat Ali Khan* \\ Department of Biotechnology, University of Science and Technology, \\ Bannu-28100, KPK, Pakistan
}

Keywords: Oligomeris linifolia, Antioxidant, Antibacterial, Antifungal activity

\begin{abstract}
Fine powder of Oligomeris linifolia was extracted with $70 \%$ methanol. Crude Oligomeris linifolia methanol extract (OLME) were assessed for antioxidant, antibacterial and antifungal characteristics. All the tested OLME showed potent antioxidant, antibacterial, and antifungal activities. The results clearly showed that Oligomeris linifolia methanol extracts is a source of potential therapeutic compounds against antibacterial, antifungal and free radical associated disorders.
\end{abstract}

\section{Introduction}

Treatment with herbal remedies is used almost in every country of the world and has been relied on to promote, support and get good human health for hundreds of years. For example, the Chinese system of traditional remedy is running like herbal medicines has been used efficiently from 2500 years, to prevent, detect and treat numerous diseases (Sucher and Carles 2008). Treatment with herbal drugs have a vital part in maintaining human health safety and improving human life from a long time. World health organization has surveyed that $80 \%$ of the world's population rely upon treatment with herbal medicines for their better health needs and these herbal medications mostly consist of plant extracts and their vigorous constituents. Several basic concepts of their therapeutic systems are still not clarified applying new methods (Mulu et al. 2015). The tribal population living in periphery of India has mostly depend upon traditional remedies and phytomedicine floras division has fundamental place in the tribal and peripheral population of India. Phytomedicine has a strong origin of both traditionally and current medications. Herbal medicine has veritable effectiveness and around $80 \%$ of peripheral population depend on it for their health care needs (Akinyemi et al. 2005). Pharmaceutical industries currently spent a significant proportion of money and energy to separate natural constituents from herbal floras, to provide safe and economically most safe medications to the population. In the late $19^{\text {th }}$ century first anti-microbial activities tests of herbal constituents of phytomedicine floras were recorded. Currently it is evaluated that western medicines consist of one half of the herbal constituents (Doughari 2006). Herbal medications are safer than pharmaceutical preparations and the crucial benefits of using herbal floras show substantial curative efficacy and more savvy treatment. Herbal floras around the world consist of numerous ingredients which has antimicrobial effects. Herbal floras constituents were utilized for the treatment of numerous ailments and these methods are the basic part of all traditional system of medications (Salwa et al. 2011). The knowledge about chemical composition of herbal extracts is essential, to find out such biochemical ingredients that have distinct beneficial impact on human body. Flavonoids, tannins, alkaloids and phenolic compounds are some of such basic biochemical composites of herbal floras. In addition, the knowledge about chemical composition of therapeutic floras would further

\footnotetext{
*Author for correspondence: <Rahmatgul_81@yahoo.com>, <nadeem.ispar@gmail.com>. ${ }^{1}$ Institute of Pharmacology, School of Pharmaceutical Sciences, Shandong University, Shandong, China.
} 
be useful for disclose of the actual significance of herbal derived remedies (Mojab et al. 2003). In traditional medication Asteracae (Artemisia sp.) are commonly utilized as a therapeutic flora (Proksch 1992). It was scientifically showed that Artemisia species wormwood improved the digestibility performance of a sheep when it was added in her diet and rice straw substituted (Ko et al. 2006). Sida rhombifolia is wildly used as a therapeutic medicine. For example, in Ayurveda its leaves and roots utilized for cure of heart diseases, all kinds of inflammations, fever and burning sensations. The roots of Sida rhombifolia improves child birth process if taken internally into the uterus and utilized for the treatment of pulmonary tuberculosis and rheumatism. The powder form of the leaves is applied as a remedy to boils and tumours. Its aerial extracts are utilized as an anti-venom remedy for snake bite and act as an abortifacient in pregnant women if taken orally (Holdsworth 1974). The phytochemical studies of Sida rhombifolia shows the presence of tannins, saponins, sterolic compounds, alkaloids, amino acids, fatty acids, carbohydrates, terpenoids, glycosides, lignans, steroids, flavonoids and phenolics (Narendhirakannan and Limmy 2010). Oligomeris linifolia belong to Resedaceae and is one of Oligomeris species. The family Resedaceae consists of 52 classes of six genera divided into three groups. Oligomeris species mainly found in North Africa, Middle East India, Pakistan, North America and Southern Europe. Habitat of the herb includes saline soils, deserts, coastline, and plain areas. It is $50 \mathrm{~cm}$ tall and an annual herb, contains linear leaves. Two phenolic acids, one sterol, five flavanols, one nucleotide and two free sugar compounds were isolated from the herb (Hussein et al. 2013). The present study was carried out for a detailed pharmacological investigation of Oligomeris linifolia methanol extracts for their antioxidant, antifungal and antibacterial activity.

\section{Materials and Methods}

The whole mature and healthy plant of Oligomeris linifolia was collected from the nearby agricultural fields of Bannu, Khyber Pakhtoonkhwa, Pakistan during April and May, 2016. The plant was carefully washed in distilled water to remove dirt and latex and cut into pieces with knives and a pair of scissors. For shade drying the plant fragments were placed and scattered on the floor above clean sheet approximately for 30 days. In a hot air oven, the plant shade dried pieces further dried for an hour at $40^{\circ} \mathrm{C}$ just before start of the extraction process to eliminate the residual moisture and to obtained fine powder of it. In a conical flask $70 \mathrm{~g}$ fine powder of the dried plant were socked in $300 \mathrm{ml}$ of $70 \%$ methanol for $72 \mathrm{hrs}$ at room temperature. Then Whatman filter paper was used for filtering the plant extracts to get methanol filtrate. Through rotary evaporator the methanol was evaporated to obtain crude. For antibacterial activity test agar well, diffusion method was used (Nisar et al. 2010). Nutrient broth was used for the test bacterial isolate and a few colonies of the bacterial isolate were transferred into it. Then the broth was placed at $37^{\circ} \mathrm{C}$ in an incubator shaker until the visible turbidity was greater than or equal to the 0.5 McFarland standard and within $30 \mathrm{~min}$ of preparation process was used. According to slandered protocol $7.5 \mathrm{mg}$ methanolic extracts of the plant were dissolved in $1 \mathrm{ml}$ of dimethyl sulfoxide (DMSO) to obtain 5.0 and $2.5 \mathrm{mg} / \mathrm{m}$.

To determine antifungal activity of the methanolic extracts of the plant the agar tube dilution assay was used as already defined (Ijaz et al. 2010). The antioxidant activity was carried out as mentioned (Nabavi et al. 2008). Following formula was used for determination of scavenging (antioxidant) activity: Scavenging $\%=[($ control absorbance-sample absorbance $) /($ control absorbance) $\times 100$.

\section{Results and Discussion}

To investigate antimicrobial activity of Oligomeris linifolia methanol extracts, its different concentrations were used against 4 different bacterial isolates viz. Staphylococcus aureus, 
Enterococcus faecalis, Salmonella typhemurium and Klebsella pneumonia. Fig. 1 shows that high concentrations of $O$. linifolia methanol extract has maximum effects against Staphylococcus aureus, Salmonella typhemurium, Enterococcus faecalis and Klebsella pneumonia as compared to other concentrations viz. 5.0 and $2.5 \mathrm{mg} / \mathrm{ml}$. Ceftriaxone $(1 \mathrm{mg} / \mathrm{ml})$ used as a positive control shows significant effects as compared to all the tested concentrations of $O$. linifolia and negative control of DMSO. Another investigation stated that plant extracts have antimicrobial manifestations due to presence of flavonoid and phenolics contents in it (Baba et al. 2015). In human being fungi causes various fungal infections. In the market different antifungal drugs are available but these pharmaceutical preparations have various side effects. Hence, researchers in current conditions are trying to prepare such type of treatments which are safe and more effective to human. From herbal floras antifungal extracts are obtained which have vital role in controlling of various fungus infections. In the present study Oligomeris linifolia methanol extracts were tested against 4 strains of fungus viz. Aspergillus flavous, A. niger, A. fumigatus and Candida albicans. Fig. 2 presented $65 \%$ inhibition of OLME against all tested fungal strains hence proved that it has strong antifungal activity. OMLE inhibited the C. albicon, A. fumigatus, A. flavus and A. niger with inhibition percentage of $71.2 \pm 1.33,67.1 \pm 1.12,61.5 \pm 1.11$ and $53.3 \pm 1.37$, respectively as compared to control of terbenafene $(1 \mathrm{mg} / \mathrm{ml})$. Some earlier reports study were same as this result (Bylka and Goslinska 2001).

Klebsiella pneumonia

- Staphylococcus aureus
Salmonella typhemorium

Enterococcus faecalis

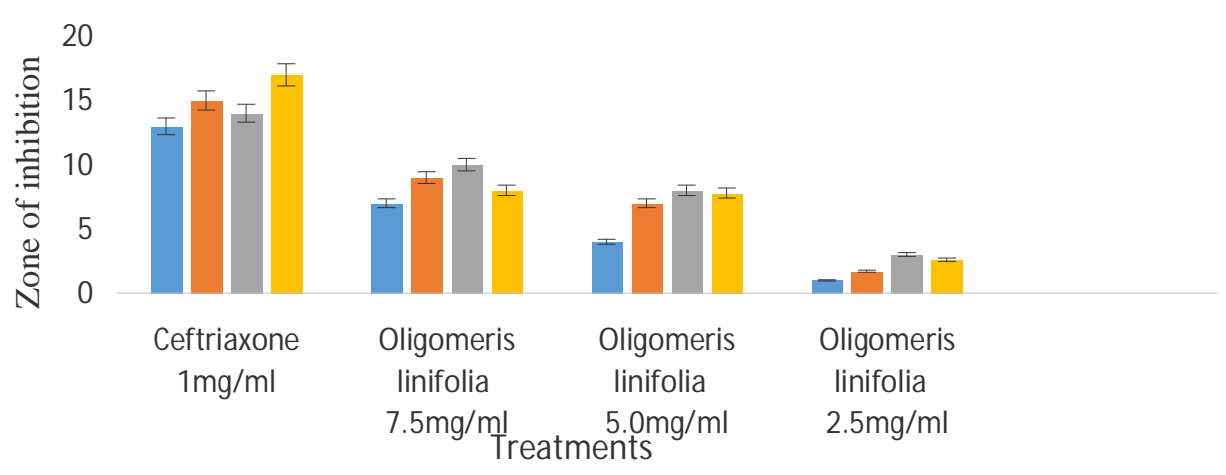

Fig. 1. Effect of methanol extract of Oligomeris linifolia against bacteria.

1,1-diphenyl-2-picrylhydrazyl (DPPH) is a free radical and from antioxidant it can attract electrons. The antioxidant activity of the Oligomeris linifolia methanol crude extract is presented in Fig 3. Graph represents a direct relationship between the concentration of methanol extract and the per cent scavenging of Oligomeris linifolia. Free radical scavenging activity of the plant at a concentration of 3 and $0.38 \mathrm{mg} / \mathrm{ml}$ was 59.5 and $21.31 \%$, respectively. The order of per cent free radicals scavenging activity is $3,1.5,0.75$ and $0.38 \mathrm{mg} / \mathrm{ml}$, respectively. Bioactive compounds are found in medicinal flora which play significant role in the cure of numerous oxidative stress causing ailments including cancer, heart disease, inflammation, diabetics and infections all over the world (Kumar et al. 2016). For treatment of various kind of ailments different floras are locally used in all over the world and have been under research to obtained active compounds for medications. Wide variety of herbal floras and other natural resources are found in Pakistan which have been used by local people for treatment various diseases including infectious diseases, skin 
diseases and gastrointestinal tract diseases as well. For research purpose, knowledge from local healers play vital part to get information about therapeutic nature of numerous herbal species. The present findings revealed that methanolic extracts of the plant Oligomeris linifolia has marked antioxidant potential (59.5 and $21.31 \%$ at 3 and $0.38 \mathrm{mg} / \mathrm{ml}$ ) concentrations, respectively. The plant Oligomeris linifolia has marked antioxidant potential which is due to phenolic and polyphenolic compounds present in it which decreases the free radicals that causes oxidative stress in living cell. Same results obtained by other researchers correlate with the present findings (Duenas et al. 2006).

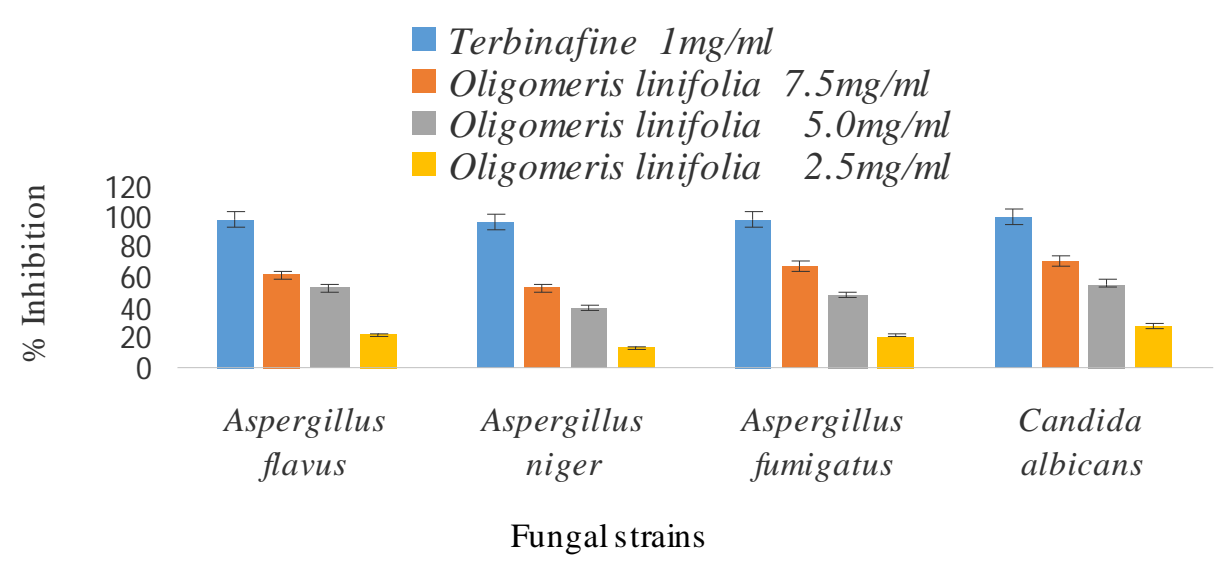

Fig. 2. Antifungal effect of Oligomeris linifolia methanolic extract on Aspergillus flavous, A. niger, A. fumigatus and Candida albicans.

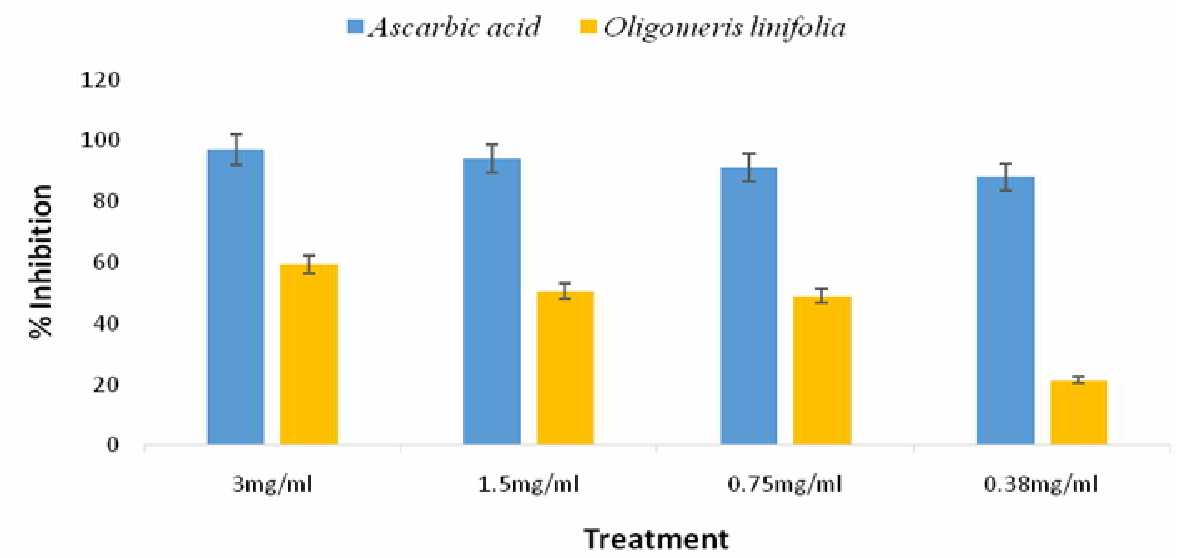

Fig. 3. DPPH free radical scavenging activity by the Oligomeris linifolia extracts.

The antioxidant, antifungal and antibacterial activities were investigated for the methanol fractions of $O$. linifolia. The present study reveals that the methanol fractions of $O$. linifolia were active against all the tested microorganisms and had good antioxidant activities. 


\section{References}

Akinyemi KO, Oladapo O, Okwara CE, Ibe CC and Fasure KA 2005. Screening of crude extracts of six medicinal plants used in South-West Nigerian unorthodox medicine for anti-methicillin resistant Staphylococcus aureus activity. BMC Comp. Alter. Med. 5: 6-13.

Baba A, Malik SA and Baba AS 2015. Determination of total phenolic and flavonoid content, anti-microbial and antioxidant activity of a root extract of Arisaema jacquemonti Blume. J. Taibah University Sci. 9: 449-454.

Bylka W, Goslinska O 2001. Determination of isocytisoside andantimicrobial activity of ethanolic extract from Aquilegia vulgaris. Acta Polon. Pharm. 58: 241-243.

Doughari JH 2006. Antimicrobial activity of Tamarindus indica Linn. Trop. J. Pharm Res. 5: 597-603.

Duenas M, Hernandez T and Estrella I 2006. Assessment of in vitro antioxidant capacity of the seed coat and the cotyledon of legumes in relation to their phenolic contents. Food Chem. 98: 95-103.

Hussein SR, Elkhateeb A, Marzouk MM, Ibrahim LF and Kawashty SA 2013. Phytochemical investigation of Oligomeris linifolia (Vahl) Macbr. (Resedaceae). Biochem. Syst. Ecol. 49:73-76

Holdsworth DK 1974. A Phytochemical Survey of Medicinal Plants in Papua New Guinea, Science New Guinea 2:142.

Ijaz A, Fozia I, Itrat F, Nisar A, Shilin C, Nighat A and Abdul M 2010. Xanthine oxidase/tyrosinase inhibiting, antioxidant, and antifungal oxindole alkaloids from Isatiscostata, Pharma. Bio. 48:716-721.

Izzotti A, Sacca SC, Longobardi M and Cartiglia C 2010. Mitochondrial damage in the trabecular meshwork of patients with glaucoma. Arch. Ophthalmol. 128: 724-730.

Kumar S, Dobos GJ and Rampp T 2016. The significance of ayurvedic medicinal plants. J. Evid. Based Complement Altern Med. pp. 1-8, 10.1177/2156587216671392.

Ko, YD, Kim JH, Adesogan AT, Ha HM and Kim SC 2006. The effect of replacing rice straw with dry wormwood (Artemisia sp.) on intake, digestibility, nitrogen balance and ruminal fermentation characteristics in sheep. Animal Feed Sci. Technol. 125: 99-110.

Mulu T, Teshale F, Gemeda S, and Sahu O 2015. Medicated Evaluation of Aloe Vera: Overview on Characteristics and Application. World J. Nut. Health 3(1): 1-7.

Mojab F, Kamalinejad M, Ghaderi N and Vahidipour H 2003. Phytochemical Screening of Some Iranian Plants. Iranian J. Pharm. Res. pp. 77-82.

Nabavi SM, Ebrahimzadeh MA, Nabavi SF, Hamidinia A and Bekhradnia AR 2008. Determination of antioxidant activity, phenol and flavonoids content of Parrotia persica Mey. Pharmacolonline 2: 560567.

NisarM, Qayum M, Raza SM, Waqar A K, Ihsan A and Zia-ul-haq M 2010. Antimicrobial screening of Impatiens bicolor royle. Pak. J. Bot. 42(1): 523-526.

Narendhirakannan RT and Limmy TP 2010. In vitro antioxidant studies on ethanolic extracts of leaf, stem and root of Sida rhombifolia L. Intl. J. Pharma. Bio. Sci. 2: 1-10.

Proksch P 1992. Artemisia. In: Hansel, R. Keller, K. Rimpler, H. Schneider, G. andHrsg (Eds.), Hagers Handbuch der Pharmazeutischen Praxis. Springer-Verlag, Berlin. pp. 357-377.

Salwa M, Abdel Rahman, Sawsan A, Abd-Ellatif, Sahar F, Deraz, Ashraf A and Khalil 2011. Antibacterial activity of some wild medicinal plants collected from western Mediterranean coast, Egypt: Natural alternatives for infectious disease treatment. African J. Biotech. 10(52): 10733-10743.

Sucher NJ and Carles MC 2008. Genome-based approaches to the authentication of medicinal plants. Planta Medica 74:603-623. 